\title{
INTERACCIÓN ENTRE POLÍTICA Y DERECHO EN LA CONFIGURACIÓN DE LAS SEGUNDAS CÁMARAS ESPAÑOLA E
}

\section{ITALIANA}

\section{Vicente A. Sanjurjo Rivo}

SUMARIO: I.- Introducción. II.- Desacuerdo político material, acuerdo de mínimos jurídico-formal sobre el modelo territorial y segunda cámara italiana. III. Acuerdo apócrifo sobre el modelo territorial y segunda cámara española. IV.- La Constitución en la Historial y su incidencia sobre las segundas cámaras en España e Italia.

\section{I.- INTRODUCCIÓN}

En el marco europeo, resulta muy llamativo que tanto el Senado español como el italiano hayan sido objeto, desde el momento mismo de su creación, de multitud de críticas y de una gran variedad de propuestas de reforma. Ambos, además, tendrían en común el haber nacido con vocación de representación territorial y a ambos se le achacaría el no satisfacer esta función primigenia. A nuestro juicio, para dar con el germen de esta disfunción habría que remontarse a sus respectivos procesos de gestación, es decir, a sendos procesos constituyentes, y a partir de ellos, como más adelante expondremos, extraer las consecuencias que se derivarían de la dinámica entre la Constitución y la historia. Quiere esto decir que las particulares circunstancias que rodearon los procesos de elaboración de las Constituciones de estos dos países en lo relativo a la organización territorial del Estado y, por extensión, al Senado, motivó, en el caso de Italia, una flagrante contradicción entre la Constitución y los primeros años de vida constitucional, y la necesidad de completar el texto constitucional en su desarrollo posterior, en el caso de España. En definitiva, veremos cómo la configuración de las segundas cámaras de ambos países se vio condicionada por una determinada coyuntura política en el momento de elaboración de las Constituciones respectivas, y cómo ello tendrá una decisiva repercusión con el paso del tiempo, una vez aprobados ambos textos constitucionales.

\section{II.- DESACUERDO POLÍTICO MATERIAL, ACUERDO DE MÍNIMOS JURÍDICO-FORMAL SOBRE EL MODELO TERRITORIAL Y SEGUNDA CÁMARA ITALIANA}

En Italia, tras la caída del fascismo en pleno desarrollo de operaciones de la II Guerra Mundial, se abrirá, como, salvando las distancias, sucederá bastantes

${ }^{1}$ Profesor de Derecho Constitucional, Universidad de Santiago de Compostela, España. 
años después en España, un proceso de transición hacia la democracia. En este período de transición se intentará retomar el ordenamiento liberal del Estatuto albertino que poco tiempo después, ya desbordado por los acontecimientos, permitirá desembocar en el régimen democrático actualmente vigente en aquel país.

Ya en estos momentos iniciales podía adivinarse que la futura organización territorial del Estado daría un vuelco radical y que la Región vendría a ocupar un lugar principal en la misma. Este brusco giro respondió a la reacción frente al tradicional centralismo del Estado liberal albertino y también como mecanismo de contención de las demandas autonomistas (y hasta separatistas) de ciertas partes del territorio cuya satisfacción obligó, incluso antes de ponerse en marcha el proceso constituyente, a la aprobación para Sicilia y el Valle de Aosta de sendas normativas autonómicas.

Toda la producción normativa de esta etapa, lo que más tarde se daría en llamar la Constitución material, fue fundamentalmente obra de los partidos políticos. En este sentido, mención especial merece el Decreto legislativo de 25 de junio de 1944, número 151, parte sustancial de ésta, que actuó como auténtica norma-puente hacia la democracia al remitir directamente a la constitución de una Asamblea constituyente. Así pues, tal y como acabamos de apuntar, los partidos políticos fueron realmente los constituyentes de la Constitución material. Y no podrían comprenderse acontecimientos de tanta relevancia como la renuncia del Rey y la institucionalización de la lugartenencia o el modo finalmente adoptado para resolver la cuestión institucional sin tener en cuenta los distintos partidos y la relación de fuerzas entre éstos. En realidad, nada se entendería de esta etapa si prescindiésemos de ellos. Por todo ello resultaba obligado el estudio de las distintas propuestas o grandes líneas programáticas que, con relación al Senado (y también a la organización territorial), planteaban los distintos partidos en este momento previo a la Constituyente. Aparte del valor que puedan tener en sí mismas, constituyen el bagaje fundamental con el que los diversos partidos acometerán la labor constituyente. Representan, en fin, puntos de partida que no

Entre la abundantísima bibliografia, concerniente tanto a la literatura historiográfica como -más específicamente- a la jurídica, referida al periodo histórico que entonces se iniciaba, puede resultar de gran utilidad la consulta, entre otros, de JEMOLO, A. C.: «Continuitá e discontinuitá costituzionale nelle vicende italiane del 25 luglio 1943», en Atti Accademia Nazionale Lincei, Roma, 1947; GuELI V.: Diritto costituzionale provvisorio e transitorio, Roma, 1950; CALAMANDREI P.: "Cenni introduttivi sulla Costituente e sui suoi lavori», en Commentario sistematico alla Costituzione italiana, dirigido por P. CALAMANDREI y A. LEVI, Firenze, G. Barbera, 1950, pp. 89-140; AMORTH A.: Problemi costituzionali: dallo Statuto albertino alla Costituzione della Repubblica, Milano, 1951; ONIDA V.: L'ordinamento costituzionale italiano dalla caduta del fascismo all'avvento della Costituzione repubblicana (testi e documenti), Bologna, 1976; AA. Vv.: La fondazione della Repubblica. Dalla Costituzione provvisoria alla Assemblea Costituente, dirigido por E. CHELI, Bologna, Società editrice II Mulino, 1979; ALleGRETTI, U.: Profilo di storia costituzionale italiana. Individualismo e assolutismo nello stato liberale, Bologna, Il Mulino, 1989; BONINI: Storia costituzionale della Repubblica, Roma, 1993; NEGRI: Storia politica italiana, Milano, 1994; y AA. VV.: Storia dello Stato italiano dall'Unità a oggi, dirigido por R. ROMANELL, Roma, Donzellli Editore, 1995.

3

Decreto legislativo de 7 de septiembre de 1945, núm. 545, relativo a la región del Valle d'Aosta, y el Real Decreto legislativo de 15 de mayo de 1946, núm. 455, de aprobación del Estatuto de Sicilia. 
podían ser soslayados en la medida en que tendrán su continuidad y concreción definitiva en sede constituyente ${ }^{4}$.

Entre los partidos italianos del centro-derecha había, con sus distintos matices, una general inclinación favorable al regionalismo. Sin embargo, ese regionalismo, más o menos entusiasta según los casos, no se traducirá en una propuesta regionalista perfectamente definida. Por el contrario, cuando se trataba de ofrecer modelos operativos que poder contrastar, apenas alcanzaban bosquejos que en absoluto daban la medida exacta y el alcance del proceso de regionalización que patrocinaban. Únicamente el rechazo del Estado federal, que se veía como un factor de disgregación del país, servía como elemento para delimitar negativamente el Estado regional que auspiciaba la centro-derecha. Probablemente por ello, cuando se conectaba la organización territorial con la configuración de la Segunda Cámara ningún grupo ofrecería un modelo de Senado auténticamente regional, de corte federal, sino que a la representación regional se superpondrán otras modalidades de representación, como la corporativa, la de intereses o la de notables y, en todo caso, se le asignarán las funciones típicamente conservadoras de Cámara de reflexión, de mejora técnica o de contrapeso de la actividad de la otra Cámara.

La izquierda italiana, en cambio, recelaba del proceso de regionalización del país por cuanto podía tener de dispersión del poder político y de entorpecimiento de la actividad planificadora, y era mayoritariamente unicameralista. En este sentido, el único punto de encuentro que mantenía con el centro-derecha sería su frontal oposición al federalismo. No obstante, socialistas y comunistas, llegado el caso -y como finalmente sucedió-, estarían dispuestos a aceptar el establecimiento de una Segunda Cámara, siempre que fuese elegida por procedimientos democráticos y estuviese desprovista de funciones conservadoras $\mathrm{y}$, a cambio, en lo que constituiría una inversión de las pautas de funcionamiento de un Senado regional al uso y una muestra más de la desconfianza que el movimiento regionalista despertaba en unos y otros, sirviese de instrumento de control de las Regiones en manos del poder central del Estado.

En ese recorrido hacia la definitiva ruptura con el ordenamiento prefascista se creó en el Ministerio para la Constituyente una "Commissione per Studi attinenti alla Riorganizzazione dello Stato", que a su vez se articuló en varias subcomisiones, la primera de las cuales, sobre "problemas constitucionales", resultó ser un magnífico banco de pruebas que anticipó los problemas y el modo de ordenar y abordar el debate que poco tiempo después emprendería el constituyente. En efecto, en esa I Subcomisión se barajaron los modelos de

\footnotetext{
Respecto a la actividad desarrollada por los distintos partidos políticos y a su creciente protagonismo en esta época, cfr., con carácter general, AA. VV.: Cultura politica e partiti nell'età della Costituente, t. I: «L'area liberaldemocratica. Il mondo cattolico e la Democrazia Cristiana», y t. II: «L'area socialista. Il Partito Comunista Italiano», dirigido por R. RUFFILLI, Bologna, Società editrice Il Mulino, 1979.

La documentación existente sobre la primera y segunda Subcomisión de la «Comisión para los Estudios relativos a la Reorganización del Estadom está recogida en D'ALESSIO, G.: Alle origini della Costituzione italiana. I lavori
}

5 
Senado regional y corporativo o de intereses, pero ya entonces, la falta de concreción respecto a la organización regional que presumiblemente acabaría por implantarse impedía proveer a la Segunda Cámara de un cierto grado de especialización funcional en orden a lo territorial, de modo que finalmente se le reservarían idénticas funciones y capacidades que a la Cámara Baja, con la evidente finalidad conservadora de poder neutralizar, llegado el caso, sus actuaciones. En realidad, la paridad entre ambas Cámaras no era más que un instrumento al servicio de las ideas más tradicionales: el bicameralismo apellidado perfecto hacía realmente efectivas las intenciones conservadoras del bicameralismo a secas.

Iniciado el proceso constituyente, y una vez aceptado el bicameralismo perfecto, el desacuerdo político de fondo sobre la estructura regional del Estado se desplazó a lo largo de las distintas fases de tramitación en la Constituyente justamente al debate sobre el modo de composición del Senado ${ }^{7}$. En efecto, las líneas de confrontación derecha-izquierda y regionalismo-antirregionalismo explicarían por sí solas, los cruces de pactos que caracterizaron el proceso constituyente italiano en esta materia y que conducirían al Senado en su configuración definitiva. De hecho, la primera de ellas (derecha-izquierda) impregnó en un primer momento el iter constituyente, lo que se tradujo en la aprobación del bicameralismo y en la equiparación funcional de ambas Cámaras.

En un momento posterior, sería, en cambio, el segundo eje (regionalismoantirregionalismo) el que (además del anticorporativismo) justificase el pacto -en cierto modo contra natura - entre los comunistas y la derecha, para de ese modo aislar a republicanos y católicos, sensibles a los postulados autonomistas. Ahora bien, debe tenerse en cuenta que también en esta fase del proceso intervino el primero de los ejes (derecha-izquierda), de manera que ambos se simultanearon y entrelazaron en una suerte de intereses comunes y a la vez profundamente contradictorios. Así, mientras el binomio regionalismo-antirregionalismo conciliaba ambos extremos del arco parlamentario en torno al colegio uninominal, el eje derecha-izquierda emergía para poner al descubierto las distintas motivaciones que inspiraban a ambos grupos: mientras la derecha patrocinaba el sistema mayoritario a fin de alumbrar un Senado estructuralmente

preparatori della «Commissione per studi attinenti alla riorganizzazione dello stato* (1945-1946), Bologna, Società editrice il Mulino, 1979.

6

Al respecto véase, por todos, el minucioso trabajo de MAGAGNOLI, S.: «Autonomie locali e regioni nei lavori per l'elaborazione della Costituzionew, en La formazione della Repubblica. Autonomie locali, regioni, governo, politica economica, S. MAGAGNOLI, E. MANA, y L. ConTE, Bologna, Società editrice il Mulino, 1998, pp. 11 y ss.

7

Con relación a la Constituyente y a los trabajos por ella desarrollados, así como a las diversas cuestiones que éstos suscitaron en sus variadas facetas, véase FALZONE, V. y GROSSI, P. F.: «Assemblea costituente italianan, en Enciclopedia del diritto, vol, III, Milano, 1960, pp. 370 y ss.; Falzone, V., PAlermo, F. y Cosentino, F.: La Costituzione della Repubblica italiana. Illustrata con i lavori preparatori e corredata da note e riferimenti, Milano, 4. ${ }^{2}$ edic., Arnoldo Mondadori Editore, 1980; AA, VV.: Scelte della Costituente e cultura giuridica, t. II: «Protagonisti e momenti del dibattito costituzionale», dirigido por U. DE SIERVO, Bologna, Societá editrice il Mulino, 1980; AA. Vv.: Fausto Gullo fra costituente e governo, dirigido por C. AMIRANTE Y V. ATRIPALDI, Napoli, Edizioni Scientifiche Italiane, 1997; y La Costituzione della Repubblica nei lavori preparatori della Assemblea Costituente:: vols. VII, VI y IV, Roma, Camera dei Deputati, Segretariato Generale, 1971. 
distinto a la Cámara Baja y en todo equiparado a ella, la izquierda lo hacía justamente por lo contrario. Y por ello algunos conspicuos representantes de la derecha apoyaron decididamente el nombramiento de una cuota de senadores directamente por el Presidente de la República, mientras la izquierda, en cambio, una vez conquistado el sufragio universal directo, pactaría con la DC el régimen electoral del Senado, desvirtuando el sistema uninominal para, de facto, asimilarlo al de la Cámara de Diputados y acortar así -aún más si cabe- las posibles diferencias entre ambas.

Sin duda, en todo este recorrido hasta alcanzar el Senado en su conformación definitiva, el papel desempeñado por el PCI como fuerza hegemónica y aglutinante de la izquierda fue absolutamente decisivo. Su trayectoria con relación al tema que nos ocupa no fue, desde luego, lineal, sino que más bien se caracterizó por una suerte de zigzag permanente, sólo en apariencia aturullado e incoherente. Así, si en un primer momento el Senado regional contó con los parabienes de los comunistas, que pretendían con ello aislar al Senado corporativo de corte católico, luego resultó para los mismos inadmisible, en cuanto que aquél (el Senado regional) era ahora, según ellos, propio de una estructura federal en absoluto trasladable, en virtud de lo dispuesto por el nuevo texto constitucional, al caso italiano. Fue entonces cuando orientaron sus preferencias, en sintonía con la derecha, hacia el colegio uninominal. Con esta alianza táctica (por otra parte, como todas las demás), los comunistas perseguían asegurarse la aprobación del sufragio universal directo frente al sufragio indirecto que patrocinaban republicanos y democratacristianos $y$, conseguido el objetivo, no tuvieron entonces el menor reparo en pactar con la DC el sistema electoral del Senado que, curiosamente, vino a desvirtuar el sistema uninominal para aproximarlo al proporcional aprobado para la Cámara de Diputados.

Pues bien, decíamos sólo en apariencia, porque tras este continuo serpenteo, se escondía una ruta bien definida, cuyo trazado, perfectamente lineal, tenía un punto de destino perfectamente preestablecido: la mayor homogeneidad posible de la composición de ambas Cámaras. Y tampoco le quedaban al PCI y a la izquierda en general muchas más alternativas: aprobado el bicameralismo y la identidad de funciones entre ambas Cámaras (binomio derecha-izquierda), el único modo de neutralizar una Segunda Cámara de tamaña potencialidad era acercar lo más posible su modo de composición al de la otra Cámara. Y ello no sólo (aunque muy principalmente para la izquierda) porque los elementos de diferenciación que pretendían introducirse para la Segunda Cámara tenían un tufo ciertamente conservador, sino también porque dos Cámaras estructuralmente distintas pero con idénticos poderes conducirían muy probablemente a la parálisis del sistema. La izquierda, en general, y los comunistas, en particular, eran conscientes de que el juego de contrapesos no debía situarse en la confrontación entre la Cámara de Diputados y el Senado, el cual, en todo caso, sería un contrapeso conservador y, en consecuencia, sólo operativo como tal cuando la otra Cámara fuese de signo progresista, sino en la dialéctica Gobierno central y ordenamiento regional. Así 
pues, podría decirse que en la asunción misma del bicameralismo perfecto está el germen de un bicameralismo redundante que, además, necesitaba serlo para su propia viabilidad, aun a costa, claro está, de su funcionalidad.

El resultado final, como no podía ser de otra manera, fue la ausencia de un modelo definido. No obedeció, desde luego, su creación a un patrón previamente establecido capaz de explicarlo y darle sentido, de manera que el producto final difícilmente podría llegar a ser congruente y armónico. De ahí, pues, que desde su nacimiento - $\mathrm{e}$ incluso antes - hasta la actualidad, y con varios intentos de reforma a sus espaldas, este Senado no deseado haya sido blanco de las más duras y severas críticas.

\section{III.- ACUERDO APÓCRIFO SOBRE EL MODELO TERRITORIAL Y SEGUNDA CÁMARA ESPAÑOLA}

Por su parte, en España, a la muerte de Franco siguió, según disponían las previsiones sucesorias, el establecimiento de la Monarquía. Mientras en Italia se auspiciaba una continuidad jurídico-formal con relación al ordenamiento liberal albertino, entre nosotros, en cambio, se pretendía respecto del ordenamiento franquista. Quizá por ello, si en el país trasalpino las primeras formulaciones de segundas cámaras se inscribían en la más pura tradición de las monarquías constitucionales, aquí, como bien pondría de manifiesto la fallida seudo-reforma Arias-Fraga, el Senado no tendría otra finalidad que la de preservar la monarquía autoritaria legada por el ordenamiento franquista y aplacar cualquier atisbo de reforma.

Como en Italia, tras la muerte del dictador no faltaron indicios que apuntaban a la cuestión territorial, en particular en su dimensión regional, como uno de los problemas candentes que merecería particular atención. Probablemente por ello, aunque en realidad no fuese más que una coartada para alcanzar otros fines, la Ley para la Reforma Política, contraviniendo la tradición unicameralista del ordenamiento franquista, acabase incluyendo una Segunda Cámara en su regulación.

Esta Ley, que quizá pudiese denominarse por su dimensión histórica como Ley de reforma para la ruptura política, incorporaba elementos demo-liberales clásicos (lo cual no era poca novedad), aunque sin desprenderse del todo de alguno de los rasgos característicos del régimen anterior, lo que, por lo demás, era perfectamente previsible si se repara en que no era más (ni menos) que una norma de transición producto del franquismo.

\footnotetext{
8

Sobre el contenido de la Ley para la Reforma Política puede consultarse, entre la abundante bibliografía sobre el tema, LUCAS Verdú, P.: La octava Ley Fundamental. Crítica juridico-politica de la Reforma Suárez, Madrid, Tecnos, 1976, pp. 75-88; GonZÁlez NAVARRO, F.: La nueva Ley Fundamental para la Reforma Política, Madrid, Servicio Central de Publicaciones, Secretaría General Técnica, Presidencia del Gobierno, 1977, pp. 37 y ss.; HERNÁNDEZ GIL, A.: El cambio politico español y la Constitución, Barcelona, Planeta, 1982, pp. 146-177; MORODO, R.: La transición política, Madrid, Tecnos, 1984, pp. 116-124; específicamente con relación a la Segunda Cámara, Vera SANTOS, J. M.: Senado territorial y presencia de notables, Madrid, Temas del Senado, 1997,
} 
Aunque la Ley en su conjunto pudiera considerarse toda ella, por su naturaleza esencialmente instrumental, como una gran disposición transitoria, en su diseño se superponen, creemos, tres planos distintos: al primero pertenecería aquella parte del articulado que recoge diversos aspectos que se pretende que perduren en el tiempo y no se agoten en la propia Ley (principio democrático, Estado de Derecho, parlamento bicameral integrado por un Congreso elegido por sufragio universal directo y un Senado territorial y de notables); el segundo lo conformarían el grupo de preceptos que se circunscriben a la organización y funcionamiento de aquellas primeras Cortes, $y$, por último, un tercer plano en que se colocarían aquellas prescripciones que tienen fijada fecha de caducidad para el día de la celebración de las primeras elecciones.

El Senado, pues, como se acaba de señalar, era concebido desde aquel primer plano como una Cámara territorial y de notables. De manera que se pretendía que ambos aspectos perdurasen y se proyectasen en la configuración de la futura Segunda Cámara.

Pero curiosamente el principio de mínima intervención de la Ley en favor de las futuras Cortes quiebra precisamente con la introducción del Senado, en la medida en que éste era ya en sí mismo una opción constituyente: nada menos que la que supone decantarse por una organización bicameral del parlamento y por un determinado modelo de segunda cámara (territorial y de notables en el caso que nos ocupa).

Así pues, el Senado era en realidad una pieza superflua y desencajada en el engranaje de la Ley para la Reforma Política y buena prueba de ello era que no había una correlación lógica entre la representación proclamada y las funciones asumidas, como el hecho también de que su configuración fuese la única parte de aquel primer plano o ámbito de regulación descrito que, contradiciendo su vocación de permanencia, sufriese alguna alteración, al suprimirse en la futura Constitución, afortunadamente por otra parte, la categoría de los senadores regios.

La transición política había sido sobre todo un decidido esfuerzo por conjugar reforma y ruptura y la Ley para la Reforma Política, su paradigma jurídico, la síntesis de ambas. El Senado no era en absoluto ajeno a esta pugna entre reforma y ruptura. De hecho, en el diseño que la Ley para la Reforma Política había perfilado para aquella Segunda Cámara podían apreciarse características de ambas tendencias: era en efecto un Senado territorial, en sentido provincial (ruptura), pero también una clásica Segunda Cámara conservadora (reforma). Solo que a diferencia de lo que sucedió en el conjunto del proceso -y que prueba una vez más su nacimiento viciado- en este caso se produjo el fenómeno inverso, pues no fue la reforma la que se puso al servicio de la ruptura,

PP. 121-127; PÉREZ TREMPS, P.: «La ley para la reforma política. Aspectos de la transición política española», en Revista de la Facultad de Derecho de la Universidad Complutense, núm. 54, 1978, pp. 137 y ss.; MARTíN OvIED̀ò, J. M.: «De la octava Ley Fundamental del Reino a la nueva ordenación constitucional española. (Exégesis técnica de la Ley para la Reforma Política)s, en Revista de Derecho Público, núms. 68 y 69, 1977, pp. 651-664; y ya con un carácter más general, SÁNCHEZ AGESTA, L.: «La nueva Ley Fundamental para la Reforma Política», en Revista de Derecho Público, núm. 66, 1977, pp. 5-12. 
sino ésta la que se subordinó a aquélla, de modo que el Senado territorial no pasó de ser sino un pretexto idóneo para dar cauce, a través del grupo de senadores regios y del sistema electoral escogido, a las demandas y pretensiones de los sectores más conservadores. Si la Ley para la Reforma Política desembocó en la ruptura con la apertura del proceso constituyente y la posterior aprobación de la Constitución, el Senado que en ella se recogía, en cambio, jamás lo consiguió, incapaz de desprenderse a tiempo de su naturaleza más conservadora.

Por todo lo hasta aquí apuntado, pareciera que esta Segunda Cámara resultase ser una malformación en aquel ordenamiento embrionario que pretendía constituir el germen de una nueva organización constitucional: mientras se procuraba que ésta estuviese cimentada sobre el principio de soberanía popular, el nuevo Senado, por el contrario, no actuaría como expresión, sino como límite de la soberanía popular. Aunque, curiosamente, si se nos permite la expresión, esa tara jamás puso en riesgo la viabilidad de aquel engendro; antes bien, era la fatal consecuencia de la carga genética heredada: el ordenamiento franquista. Tan desdichada génesis marcará sin duda, como veremos, su sino: el de ser una institución controvertida, desprestigiada y, en algunos casos, denostada.

Mientras en el ámbito de lo jurídico (la Ley para la Reforma Política) la reforma y la ruptura se simultaneaban, en el campo de lo político (la negociación) se sucedían en el tiempo. Si prestamos atención a este segundo aspecto, comprobaremos como hasta la aprobación de la Ley para la Reforma Política se pactó la reforma con los sectores afines al régimen, para a continuación pactar la ruptura con la oposición democrática. A partir de ese momento los distintos partidos políticos adquirirían un creciente protagonismo a pesar de que por entonces, en general, no disponían de fuertes estructuras organizativas ni de gran implantación. Pues bien, todos los partidos, o al menos los más señalados, por convicción o por pura resignación, coincidían en la necesidad de acometer una tarea descentralizadora y poner fin a un centralismo entonces ya obsoleto y agotado. En lo que ya no había tanta unanimidad era en el modo de llevarla a cabo: el qué concitaba el acuerdo de todos, pero no así el cómo. Y con relación a este segundo aspecto, las diferencias que se suscitaban no eran consecuencia de la confrontación de modelos territoriales perfectamente definidos, sino más bien de prospecciones incipientes sobre la materia: el centro-derecha no pasaba de un regionalismo brumoso e impreciso; la izquierda, vacilante, oscilaba entre la connivencia con el nacionalismo (diferenciación) y el proyecto racional-cartesiano del federalismo (igualación). Pero ni siquiera en este caso el Estado federal se ofrecía como un modelo perfectamente definido y acabado desde el inicio, sino que al diferirlo en el tiempo se convertía en una aspiración, casi en un anhelo. Sin embargo, aquellas diferencias se bastaban por sí solas para poner de manifiesto una evidencia: que entre el Estado regional difuminado de AP y las propuestas federales de la izquierda mediaba un abismo; tanto que se hacía inviable un acuerdo político de mínimos sobre un concreto modelo territorial. Por eso cuando se brindaba alguno (como el de la organización federal) no se hacía con intención de aplicación 
inmediata (que la ausencia de transacción política de fondo impedía), sino retardada.

Así las cosas, se podían contemplar tantos senados como pautas descentralizadoras: a la descentralización difusa de AP acompañaba un senado confuso en el que convivía una multiplicidad de representaciones dispares; a la de base regional preconizada por UCD seguía el correspondiente Senado de composición regional, y, en fin, el propósito federalista de la izquierda se coronaba con el consabido Senado federal. Lo curioso era que siendo todos ellos, y cada uno a su modo, senados territoriales, ninguno de ellos (con la honrosa excepción de la propuesta comunista) pudiese definirse como funcionalmente territorial. Sin embargo, no tenían funciones especializadas en orden a lo territorial porque probablemente no podían tenerlas. Como nadie tenía un modelo territorial perfectamente perfilado, y si lo tenía (el Estado federal) no era más que para aplazarlo en el tiempo, malamente se podía presentar un senado completamente acabado: si la organización territorial del Estado estaba por completar, la configuración territorial del Senado debía ser por fuerza incompleta. Darle poderes efectivos en esas circunstancias sería introducir un elemento de tensión ( $y$ de incongruencia) en el sistema; lo funcional, pues, era hacerlo absolutamente disfuncional. Y entre tanta confusión, los distintos partidos políticos se aplicaron en las tareas constituyentes .

El debate constituyente se había iniciado con el alumbramiento de dos textos (el Borrador y el Anteproyecto) que se inclinaban por un modelo territorial basado en los principios de generalización e igualación autonómicos. Del primero daba buena cuenta precisamente la configuración decididamente autonómica de la Segunda Cámara (si por autonómico, y no simplemente partidista, puede entenderse un Senado elegido casi en su integridad por las asambleas legislativas autonómicas). Del segundo, el establecimiento de una única vía de acceso a la autonomía (aunque en verdad tampoco aquí hubo estrictamente un solo procedimiento de acceso como tampoco después, a partir del Informe de la Ponencia, habría solamente dos sino bastantes más), la disposición de un procedimiento único de elaboración de los estatutos de autonomía, la homogeneidad institucional y el sistema de lista única de distribución de competencias.

En materia competencial, sin embargo, el principio de igualación parecía poder tambalearse. Sin lugar a dudas el sistema de lista única confería a los

Sobre las posiciones que, con relación a estas cuestiones, mantenian por entonces los cuatro grandes partidos de ámbito nacional, cfr. DE BLAS GUERRERO, A.: «UCD, PSOE, PCE y AP; las posiciones programáticas , en Los partidos políticos en España, R. MORODO Y OTROS, Barcelona, Labor, 1979; II Congreso Nacional de Alianza Popular, 1978; DE BLAS GUERRERO, A.: «El problema nacional-regional español en los programas del PSOE y PCE», en Revista de Estudios Políticos (Nueva Época), núm. 4, 1978; BuSTELO, F. Y OTROS: PSOE, Barcelona, Avance, 1976; XXVII Congreso del Partido Socialista Obrero Español, edición a cargo de A. GUERRA, Barcelona, Avance, 1977; Manifiesto.Programa del Partido Comunista de España, Madrid, editado por la Comisión Central de Propaganda del Partido Comunista de España, 1977; SOLf́. TURA, J.: Los comunistas y la Constitución, Madrid, Forma Ediciones S. A., 1978; y, del mismo autor, «La Constitución y la lucha por el socialismon, en La izquierda y la Constitución, AA. VV., Barcelona, Taula de Canvi, 1978. 
distintos Territorios Autónomos un amplio margen y teóricamente las mismas posibilidades (igualdad) a la hora de asumir competencias: en principio podrían hacerse con todas aquéllas que previamente no se hubiesen reservado al Estado en esa lista única. Todos ellos, sin distinción, podrían querer (principio dispositivo) lo más, $y$, justamente por ello, podrían también querer lo menos. En cualquier caso, desde un punto de vista jurídico al menos, todas las regiones autónomas podrían abastecerse del mismo arsenal competencial (igualación); de no hacerlo, provocando distintos abanicos competenciales (diferenciación), no sería por imposibilidad jurídica, sino por la libre utilización que cada una de ellas hiciese del principio dispositivo. En eso, además, se aproximaba bastante al esquema federal arquetípico en el que la Constitución federal únicamente recogería aquellas materias sobre las que la Federación se reserva la competencia y apenas se ocuparía de los Estados federados, excepto en lo concerniente a su participación en la toma de decisiones de la Federación. Así pues, el abanico competencial de un Territorio Autónomo quedaría fijado inicialmente en su respectivo estatuto de autonomía aunque posteriormente sus contornos podrían sufrir variaciones a través de las distintas técnicas de descentralización de competencias exclusivas $-\mathrm{y}$ no excluyentes- del Estado. Pues bien, tanto en un caso como en otro, ya fuese por vía estatutaria o extraestatutaria, la asunción de competencias por los Territorios Autónomos estaría basada en la negociación y en la bilateralidad: en ambos casos el principio dispositivo debía supeditarse a la negociación bilateral, cuyo contenido definitivo quedaría a expensas de su ratificación por el poder central (aprobación por las Cortes de los estatutos de autonomía) o de un acto volitivo del propio Estado (delegación o transferencia de competencias estatales). Y en esa negociación faltaba una premisa que normalmente se da en los más reputados Estados federales: la presencia de dos grandes partidos con implantación en toda la Federación que galvanicen los elementos de cohesión y unión entre las partes federadas. De ahí que determinados Territorios Autónomos con partidos cuya matriz ideológica radicase en la exaltación de la diferencia y que, a su vez, estuviesen en situación de condicionar esa negociación, pudiesen acceder a un haz competencial más amplio que todos los demás.

Aunque deba reconocerse que nada de esto se desprendía directamente del Borrador o del Anteproyecto y que, como se acaba de indicar, en todo caso la última palabra en esa negociación correspondía al poder central del Estado, lo cierto es que la diferenciación estuvo presente desde los inicios mismos del debate constituyente. Así, cuando la Ponencia discutía los diversos aspectos controvertidos que el proceso estatuyente planteaba, ya se ponían encima de la mesa propuestas referidas a "la posibilidad de que [existiesen] disposiciones especiales para la elaboración del Estatuto en regiones concretas" ${ }^{10}$, lo que sin duda constituía un claro precedente de lo que luego sería la disposición transitoria segunda del texto constitucional definitivo.

Minuta de la Ponencia de Constitución en su reunión del día 26 de octubre de 1977, Actas de la Ponencia constitucional, publicadas en Revista de las Cortes Generales, núm. 2, 1984, p. 303. 
En definitiva, en el Borrador y el Anteproyecto había un claro dominio de los ejes generalización-igualación, pero tampoco eran completamente ajenos, tal y como se acaba de indicar, al de diferenciación, ni aun al de no-generalización o limitación de las autonomías, pues la creación de los Territorios Autónomos quedaba supeditada al ejercicio de un derecho, es decir, regía para su constitución el principio dispositivo o de voluntariedad: no había un verdadero modelo territorial construido sobre la base de principios claros e inequívocos; en realidad, pues, nunca hubo un diseño territorial perfectamente definido, ni siquiera cuando más parecía que lo había. Y de algún modo en esas dudas e indefiniciones habría que buscar una de las causas posibles de que ambos textos planeasen una Segunda Cámara resueltamente autonómica en lo estructural pero deficientemente autonómica en lo funcional. Desde esta segunda perspectiva, el Senado no se perfilaba como una Cámara activa, con iniciativa propia, sino más bien como una instancia de garantía de la autonomía -que no autonómica- que por la naturaleza misma de sus actuaciones tenía un carácter excepcional. Con este diseño funcional que recorrerá con leves modificaciones los distintos textos producidos a lo largo de los trabajos constituyentes se terminaba por concluir siempre en el mismo sitio: en el de una Segunda Cámara desprovista de especialización funcional, ancilar en sus relaciones con el Congreso. Y ello tenía el efecto perverso de construir siempre, más allá de su composición, un Senado redundante; pero al tiempo tenía la indudable virtud de amortiguar en última instancia las dudas y vacilaciones que ensombrecían el modelo territorial y que encontrarán su justo reflejo en la dimensión orgánica de la Segunda Cámara.

Pero probablemente no se agotase aquí la explicación de esta contradicción. Porque lo cierto era que un Senado estructuralmente diferenciado y dotado de poderes efectivos contrariaba tanto a los grandes partidos estatales como a los nacionalistas. La territorialización del poder político podía cabalmente generar en las distintas regiones autónomas sistemas de partidos propios y peculiares y la consiguiente proliferación de fuerzas políticas de corte regionalista, sobre todo si se tiene en cuenta que por entonces los grandes partidos nacionales estaban lejos de tener una implantación plenamente consolidada. Con el establecimiento del sistema de representación proporcional para la elección de los distintos parlamentos regionales se aseguraba la traslación más o menos fidedigna de esos particulares sistemas de partidos a las distintas asambleas, y, de paso, al Senado, ya que previsiblemente la mayoría de sus miembros vendrían designados por éstas, respetando, a su vez, proporcionalmente la relación de fuerzas existente en cada una de ellas. ¿El presumible resultado de todo ello? Una Cámara compuesta por un abigarrado mosaico de fuerzas políticas que la harían especialmente ingobernable. Pero es que además debía repararse en que la duración del mandato de los senadores así elegidos quedaba vinculada a la de la asamblea que los designaba. No podía descartarse, sino más bien todo lo contrario, que las elecciones regionales acabasen por celebrarse escalonadamente en el tiempo y no simultáneamente y las fluctuaciones de la orientación política general que inevitablemente se suceden en el tiempo terminarían entonces por reflejarse en la 
Segunda Cámara, con la ayuda del sistema proporcional empleado en los distintos eslabones de la cadena electiva (asambleas regionales primero, y designación de senadores por éstas después). Si a todo ello se añade que el sistema de representación proporcional se aplicaría previsiblemente también al Congreso, el cuadro resultante quedaría aproximadamente como sigue: que el partido que dispusiese de mayoría - presumiblemente relativa - en la Cámara Baja debería contar con otra Cámara que a lo peor resultaba ser completamente incontrolable, o que a lo mejor quedaba bajo el control -dada su finísima sensibilidad a los vaivenes electorales - de un partido distinto al hegemónico en el Congreso y sostén del Gobierno, el cual, además, en ningún caso podría disolver esa difícil o arisca Segunda Cámara. En esas condiciones, dotar al Senado de poderes efectivos en materia autonómica o en lo que fuese hubiese sido para los partidos estatales cuando menos arriesgado. Esta última circunstancia, o sea, la utilización del sistema proporcional para el Congreso y la consiguiente dificultad para alcanzar mayorías suficientemente amplias, resultaba particularmente provechosa para los partidos nacionalistas. De cumplirse esas previsiones, los partidos nacionalistas tendrían que asegurarse una presencia en esa Cámara de la suficiente entidad (cosa que el sistema de representación proporcional facilitaba) como para poder condicionar las precarias mayorías que en ella se constituirían. No se trata de una hipótesis o de una simple elucubración. Lo decía el mismo Roca al hilo del debate sobre la institución de la moción de censura constructiva: «Además de ser un modo eficaz de asegurar una continuidad en el Gobierno, el método nos parece especialmente válido para nuestro panorama político [...] en el que la previsible configuración de dos grandes fuerzas políticas no mayoritarias, tenderían a votos de censura no constructivos» ${ }^{11}$. Alcanzado ese objetivo, los partidos nacionalistas se encontrarían en una posición inmejorable para poder negociar (elemento éste crucial en el nuevo modelo territorial) en el Congreso de los Diputados los diversos aspectos del Estado autonómico. En realidad, pues, un Senado funcionalmente territorial, plenamente territorial, además de inviable en aquel momento, no interesaba a nadie.

Con el Informe de la Ponencia tuvo lugar una inversión de principios, pues aunque de momento parecía seguir primando -más que otra cosa por el impulso que por entonces tomaba la política de las preautonomías ${ }^{12}$ - el de la

11

ROCA I JUNYENT, M., «Una primera aproximación al debate constitucional», en La izquierda y la Constitución, (n. 9 in fine) p. 42 (cursivas nuestras).

12

Entre septiembre de 1977 y octubre de 1978, es decir, en poco más de un año se crearon catorce preautonomías que coincidirían con las actuales comunidades autónomas, con las únicas excepciones de Madrid, La Rioja, Cantabria (cuya organización como entidades uniprovinciales o incorporación a otras comunidades autónomas se discutía por entonces) y Ceuta y Melilla. Esta proliferación de las preautonomías sin duda preconcebía el futuro mapa autonómico por mucho que los sucesivos textos constitucionales continuasen formalmente moviéndose en la dialéctica de la generalización-no generalización autonómica. Pero además aquellos regímenes provisionales de autonomía, aunque de forma muy elemental, anticiparian la futura organización institucional un máximo órgano colegiado (Consejo, Junta, etc.) que designaba a un Presidente (salvo en el caso de la Generalidad) que, a su vez, disponía de un órgano colegiado de gobierno-y el reparto de competencias, pues, aun cuando carecían de potestades legislativas, se arbitraron unas Comisiones mixtas paritarias para el traspaso de 
generalización autonómica, el de la diferenciación pasaba a un primer plano: la diferenciación que había anidado en los diversos textos constitucionales que hasta entonces se habían sucedido en el transcurso del iter constituyente permaneciendo en ellos en estado letárgico, reaparecía ahora con toda su fuerza en la escena constituyente para no abandonarla ya nunca más.

En efecto, el modelo autonómico se articulaba ahora alrededor de dos regímenes - el ordinario y el especial- perfectamente diferenciados, que no se reducían a dos vías de acceso, ya que eran algunas más, ni tan siquiera a dos procedimientos estatutarios, pero sí a dos tipos de autonomías: unas, las de régimen especial, con una organización institucional perfectamente determinada que reproduciría la del poder central del Estado y con un marco competencial abierto que tendría por único límite las competencias del Estado; las otras, las de régimen ordinario, en cambio, quedarían huérfanas de cualquier precisión institucional y su abanico competencial se reducía a una lista tasada de materias en donde no se aclaraba siquiera si las competencias sobre ellas serían de naturaleza legislativa o puramente ejecutiva, lo que, a su vez, engarzaba con aquella indefinición institucional, al no puntualizarse si esta modalidad de autonomías dispondría finalmente de asambleas legislativas. En definitiva, con el Informe de la Ponencia se esbozaban dos tipos de entes territoriales: unos de descentralización política y autonomía plena y otros de descentralización administrativa y autonomía restringida.

Así las cosas, y con independencia de la incertidumbre que se cernía sobre la mayor parte de las autonomías, las de régimen ordinario, afectadas de una llamativa indefinición institucional y de una cierta provisionalidad, al quedar su ámbito competencial sujeto a revisión una vez transcurridos cinco años, lo cierto era que dejaba de tener sentido un Senado de composición autonómica cuando las autonomías en él representadas participaban de naturalezas tan radicalmente distintas que rompía con la lógica de un Senado de corte federal. Y por eso, de la indefinición inicial del Informe de la Ponencia reflejo de las indecisiones y resultado de las consecuencias derivadas del nuevo modelo territorial, se evolucionó hacia un Senado fundamentalmente provincial (que a su vez coincidió con un progresivo aumento de la importancia de la provincia en el debate constituyente $^{13}$ ) y solo marginalmente autonómico, que será el que finalmente acabe sancionando la Constitución.

Por otra parte, la falta de especialización funcional que en el diseño del Senado del Borrador y el Anteproyecto no casaba muy bien, ahora empezaba a encajar perfectamente, pues los grandes temas que llevaban aparejados cierto grado de autonomía política no podrían dirimirse en un foro donde presumiblemente

servicios del Estado a los distintos entes preautonómicos. Sobre el particular véase, sobre todo, Cl.AVERO ArÉvalo, M.: España, desde el centralismo a las autonomias, Barcelona, Planeta, 1983.

13

Sobre el particular véase SÁNCHEZ FERriz, R. y SEVILl.A MERINO, J.: «La provincia y el Senado en la Constitución española de 1978\%, en Estudios sobre la Constitución española de 1978, Valencia, Universidad de

Valencia, Secretariado de Publicaciones, 1980, pp. 425-433. 
buena parte de los entes territoriales en él representados carecerían de la misma, sino bilateralmente entre el poder central del Estado (el Congreso de los Diputados) y la entidad territorial en cuestión provista de autonomía plena. Así pues, aquellas dudas y vacilaciones sobre el modelo territorial que provocaron un brusco giro en la configuración orgánica de la Segunda Cámara, no se tradujeron, en cambio, en alteraciones sustanciales en su vertiente funcional. De alguna manera, aquellos titubeos y oscilaciones que podrían tener (y que de hecho tuvieron en su dimensión orgánica) su lógico correlato en la configuración del Senado, quedaban neutralizados al perfilar una Segunda Cámara prácticamente inservible. En ese sentido y paradójicamente, su principal virtud era su inutilidad, o de otro modo, se diría que era útil en cuanto que inútil. Y será, en fin, esta caracterización funcional del Senado la que, como se ha visto, se mantendrá con leves modificaciones hasta el momento de la aprobación de la Constitución.

En materia de organización territorial del Estado, el carácter ambiguo y difuso de nuestra transición política encontró en la dimensión jurídica del proceso constituyente un fiel reflejo: las Cortes salidas de las elecciones del 15 de junio de 1977 no actuaron en lo relativo a la distribución territorial del poder como unas auténticas Cortes Constituyentes; no operaron conforme al principio de exclusividad que caracteriza la labor constituyente, y así, mientras apostaban en el Borrador y el Anteproyecto por la generalización e igualación autonómicas, el Gobierno, por contra, desplegaba su propia política regional basada en la excepcionalidad y la bilateralidad -las preautonomías- que, inevitablemente, incidiría en los trabajos constituyentes. Y si no procedieron como Constituyentes, tampoco resolvieron como tales, es decir, tampoco adoptaron una verdadera decisión constituyente: en lo concerniente a la estructura territorial no se cerró ningún acuerdo, sino que se abrió un proceso en el que la Constitución no era más que una etapa.

De las tres grandes decisiones que el constituyente debía afrontar, a saber, la conformación de un régimen democrático pluralista, el establecimiento de una monarquía parlamentaria y la descentralización territorial del poder, sólo en torno a las dos primeras había al iniciarse el proceso constituyente un acuerdo en positivo; en cambio, con relación a la tercera - a la estructura territorial del Estado- no había más que, a lo sumo, un acuerdo en negativo, esto es, lo que en modo alguno podía ser la futura organización territorial del nuevo Estado, o sea, un Estado centralista. Esta ausencia de un acuerdo político positivo vendría a explicar las oscilaciones y giros bruscos que, como se ha visto, experimentó la cuestión territorial a lo largo del debate constituyente. Por el contrario, los distintos aspectos técnico-jurídicos relativos a la democracia pluralista y a la monarquía parlamentaria fueron modulándose y matizándose conforme avanzaba la tarea constituyente y encontraron en la Constitución su culminación. La cuestión relativa a la estructura territorial, sin embargo, al carecer de esa previa decisión política positiva al iniciarse el debate constituyente y tampoco al darse con ella en el transcurso del mismo, no encontró en la Constitución más que una etapa de un recorrido más amplio. 


\section{LA CONSTITUCIÓN EN LA HISTORIA Y SU INCIDENCIA SOBRE LAS SEGUNDAS CÁMARAS EN ESPAÑA E ITALIA}

En definitiva, tanto en Italia como en España, al abordar lo que se presentaba como ineludible reorganización de la estructura territorial, el constituyente de uno y otro país tropezaba con el mismo obstáculo: la ausencia de un acuerdo político previo sobre el modo de articular aquella necesaria reordenación territorial. No obstante, quizá debido a la necesidad perentoria de transformar el obsoleto Estado centralista y a las posibilidades que la organización regional podía ofrecer como vivero de una nueva clase política que se antojaba indispensable después del período fascista, en un determinado momento en el desarrollo de los trabajos constituyentes, y sobre la base de un común rechazo del Estado federal, todos - regionalistas y antirregionalistas - acordaron, en virtud de una decisión de compromiso, el establecimiento de un Estado regional, fundado en los principios de generalización (confección de un mapa regional) y diferenciación (regiones de estatuto especial y regiones de estatuto ordinario). En España, en cambio, este desacuerdo político de partida no se logró superar en el transcurso del proceso constituyente, pero a diferencia de lo que sucedió en Italia donde se salvó con una decisión de compromiso, desembocaría en lo que, según la teoría del célebre jurista alemán Carl Schmitt, sería un compromiso apócrifo ${ }^{14}$ : el constituyente decide ciertamente posibilitar la descentralización (con la mente puesta sobre todo en el País Vasco y Cataluña), pero en cuanto a la manera global de articularla no pasa de concordar aparentemente principios antagónicos e incompatibles entre sí (generalización-limitación de las autonomías; igualacióndiferenciación entre ellas), y de ese modo deja sin contenido la decisión constituyente que queda diferida en el tiempo, o lo que es lo mismo, remitida a la historia.

No obstante, la discrepancia política de fondo que se escondía detrás de aquella decisión de compromiso o pacto de mínimos que sobre la estructura territorial del Estado había alcanzado el constituyente italiano, se trasladó justamente al debate que éste desplegó sobre el Senado, que discurriría sobre los ejes derecha-izquierda (o diversidad-homogeneidad del color político de la Segunda Cámara con relación al de la Cámara de Diputados) y territorialidad-no territorialidad (esto es, según la orientación regionalista o antirregionalista de unos y otros). En el caso de España, sin embargo, esa divergencia política de base encontró su reflejo no sólo en el debate constituyente sobre el Senado, sino también en el desarrollado con relación a la propia organización territorial del Estado. Ambos procesos constituyentes representan, pues, una buena prueba de cómo las estrategias de los distintos actores políticos y los condicionamientos políticos de cada momento histórico determinan el derecho positivo; en definitiva, de cómo el derecho se supedita a la política.

${ }^{14}$ Vid. SCHMitT, C.: Teoría de la Constitución, (traducción de F. Ayala), Madrid, Alianza Editorial, 1982, pp. 54-57. 
Por otra parte, tanto en Italia como en España, ese inicial desencuentro político sobre la estructura territorial del Estado acabó además proyectándose en la historia. En el caso de Italia, provocando contradicciones evidentes entre la Constitución y la propia historia. Así, la disposición transitoria VIII de la Constitución establecía el plazo de un año para la formación de los Consejos regionales de régimen ordinario, pero hubo que esperar más de veinte años para asistir a las primeras elecciones de los mismos; tres años era el plazo que fijaba la disposición transitoria IX para que el Estado adecuase su legislación a las exigencias de la descentralización, pero tal adaptación no podría darse por ultimada hasta, por lo menos, el Decreto del Presidente de la República de 24 de julio de 1977, núm. 616, dictado en ejecución de la delegación efectuada en virtud del artículo $1 .^{\circ}$ de la Ley de 22 de julio de 1975, núm. 382. En efecto, durante la primera legislatura republicana el único paso que se había dado en la dirección de acometer la reforma regional prescrita por la Constitución para el conjunto del país (adviértase que los estatutos de las regiones de régimen especial habían sido ya aprobados en 1948) lo constituyó la ley de 10 de febrero de 1953, núm. 62, relativa a la constitución y funcionamiento de los órganos regionales, pero no tendría virtualidad práctica alguna hasta quince años después cuando se establecieron las modalidades de elección de los titulares de los Consejos regionales, y poco más tarde se dispusieron los medios financieros de los que habrían podido disponer las distintas regiones para su funcionamiento efectivo. Se produjo, pues, un evidente retraso en la implementación del Estado regional constitucionalmente previsto al quedar en suspenso, durante más de veinte años, el ordenamiento regional, lo cual, por otra parte, sería absolutamente impensable en materia, por ejemplo, de derechos fundamentales o de organización institucional del Estado, aunque naturalmente en ambos casos la correspondiente traducción jurídico-formal descansaba en un previo acuerdo político que justamente faltaba en punto a la organización territorial. Y, paradojas de la historia, aparte las dudas de la clase política sobre el instituto regional o las resistencias burocráticas a la puesta en marcha de tan radical transformación de la estructura del Estado, lo cierto es que la hegemonía de la Democracia Cristiana, que en la etapa constituyente se había significado por su querencia regionalista, en los años que siguieron a la aprobación de la Constitución, dificultó la implantación de la reforma regional, de la misma manera que el empuje y la creciente presión a finales de los años sesenta y principios de los setenta de socialistas y, sobre todo, comunistas, que en el transcurso del período constituyente se habían distinguido por sus recelos regionalistas, facilitó la puesta en funcionamiento de la organización regional. En fin, fue la historia la que acabó de perfilar el mapa regional italiano y, en consecuencia, de cerrar la distribución territorial: a comienzos de los años sesenta, cuando las particulares circunstancias tanto de Derecho internacional como interno relativas a la zona de Trieste lo permitieron, se creaba una quinta región de estatuto especial, Friul-Venecia-Julia, y pocos meses después se desdoblaba en dos regiones distintas los Abruzos y el Molise. 
En España, por su parte, la ausencia de una auténtica decisión constituyente sobre el modo general de conformar territorialmente el Estado sobre todo con relación a los territorios no comprendidos en la disposición transitoria segunda para los que, en cambio, sí parecía reservarse un régimen de autonomía plena (País Vasco, Cataluña y Galicia), debió ser suplida por la historia a través de un proceso ulterior, el estatuyente. Y nada más comenzar este proceso, el episodio de Andalucía, que acabaría alcanzando a través del procedimiento de acceso agravado el régimen de autonomía plena, desbarataría las previsiones iniciales de diferenciación entre los territorios de la disposición transitoria segunda (entre los cuales, a su vez, se establecerían diferencias) y, en su caso, Navarra (por incorporación al Consejo General Vasco o al régimen autonómico que lo sustituyese) y todos los demás. Con ello quebraba la identificación auspiciada por el principio de diferenciación entre nacionalidades y los territorios de la disposición transitoria segunda, que gozarían de una autonomía plena, frente a las regiones, el resto, que no dispondrían más que de una autonomía restringida. Así las cosas, los Acuerdos Autonómicos de 1981 disiparon, por una parte, las dudas sobre la generalización autonómica al extender la autonomía a todo el territorio nacional (con la excepción de Ceuta y Melilla) y, sobre todo, por la otra, confirieron identidad sustancial a la naturaleza de los distintos regímenes autonómicos pues, al extender a todas las autonomías la organización institucional que inicialmente el artículo 152. 1 de la Constitución reservaba a las de régimen especial y, en consecuencia, también las asambleas legislativas, se presuponía la autonomía política de todas ellas: una vez más, se deshacía la dualidad entes de descentralización política-entes de descentralización administrativa que el principio de diferenciación, predominante al tiempo de aprobarse la Constitución, propugnaba. La diferenciación competencial, la única que básicamente perduraba, podría sin embargo, en virtud del artículo 148. 2 de la Constitución, neutralizarse una vez hubiesen transcurrido cinco años. Y así ocurrió: superado este plazo, la presión ejercida por las autonomías entonces llamadas de vía lenta desembocó en la firma de unos nuevos Acuerdos, los del 92, que, como antes los del 81, actuaron como verdaderos límites extrajurídicos del principio dispositivo, y en la posterior reforma estatutaria que supondría la práctica equiparación competencial de todas las autonomías y la superación de las limitaciones institucionales que los Acuerdos de 1981 imponían a las autonomías del $143^{15}$. Al cabo del tiempo, pues, sobrevino una forma de organización territorial diametralmente opuesta a la ideada en el momento de aprobarse la Constitución: entonces pervivía la duda sobre una eventual generalización de las autonomías y, desde luego, se apostaba por la diferenciación entre ellas; luego, en lo que constituiría una auténtica inversión de los principios preponderantes relativos a la estructura territorial operada por la

15

Sobre el contenido pormenorizado y sentido último de estas restricciones, véase BLANCO VALDÉs, R. L.: «El Estado federal interminables, en El estado de las autonomías en el siglo XXI: cierre o apertura indefinida, coordinado por F. GARCía dE CORTÁZAR, Madrid, Fundación para el Análisis y los Estudios Sociales, 2001, pp. 176-179. 
historia, y hasta cierto punto una retrotracción a los inicios del proceso constituyente, despejadas las dudas sobre la generalización al extenderse el régimen autonómico por todo el territorio (incluidos ahora Ceuta y Melilla), la organización autonómica se escoraría abiertamente hacia la igualación entre los distintos entes autonómicos.

Naturalmente, como bien puede suponerse, nada de todo ello fue ajeno a las Segundas Cámaras de ambos países. En Italia, aquel Senado de compromiso en el que había desembocado el proceso constituyente resistió sin demasiadas dificultades y sin suscitar problemas de alcance, justamente por su carácter redundante, esos más de veinte años sin ordenamiento regional siendo supuestamente una Cámara regional, o cuando menos elegida sobre base regional. De aquella contradicción entre la Constitución y la historia salía el Senado indemne, $\mathrm{y}$ además sin provocar desajustes graves (más allá de los que se derivarían de su naturaleza eminentemente superflua) en el conjunto del sistema constitucional. Sin embargo, a medida que, a comienzos de los años setenta, iba tomando cuerpo el ordenamiento regional, más evidente se hacía la ausencia de adecuados mecanismos de colaboración y de participación regional (entre ellos, y acaso muy principalmente, la Segunda Cámara) en las decisiones del poder central del Estado: aquel Senado, que había salvado las contradicciones entre la Constitución y la historia, no pudo en cambio ocultar sus evidentes deficiencias que emergieron a la superficie en cuanto Constitución e historia empezaron a confluir. A partir de entonces se extendió el convencimiento de la imprescindible reforma del Senado, pero ésta chocaba con no pocos obstáculos. Entre ellos, la debilidad endémica de las distintas fuerzas políticas o la dificultad de reforma ínsita a cualquier Constitución rígida, pero también la necesidad de alcanzar un acuerdo político previo desde el que poder abordar con ciertas garantías una modificación de la distribución territorial. Las leyes constitucionales de revisión de la Constitución, núm. 1 de 1999 y núm. 3 de 2001, acometieron esa reforma de la estructura territorial del Estado, acercándola por cierto en no pocos aspectos a la española, pero sin embargo no puede darse la cuestión por cerrada, toda vez que la última reforma fue aprobada con la oposición de la coalición electoral que resultó luego vencedora en las elecciones legislativas de mayo de 2001 y que todavía sigue pendiente la cuestión de la reforma del Senado ${ }^{16}$.

En el caso de España, en fin, el proceso constituyente afluyó hacia un Senado de circunstancias que se correspondería con los principios informadores de la organización territorial predominantes en el momento de aprobarse la Constitución. Mientras la Constitución en materia territorial abría un proceso, cerraba un Senado conforme a las coordenadas dominantes (o sea, generalización, aunque con reservas, y diferenciación) del diseño territorial en el momento de su aprobación que, por lo demás, guardaba un extraordinario (y sorprendente) parecido con la Segunda Cámara que meses antes había planeado la Ley para la

16

Cfr., por todos, sobre esta reforma, OLIVETTI, M. y GROPPI, T.: La Repubblica delle autonomie. Regioni ed enti locali nel nuovo titolo V, Torino, G. Giappichelli Editore, 2001. 
Reforma Política, y es que, en cuanto a la estructura territorial del Estado que tanto se quería ligar con la configuración del Senado, casi se está al aprobarse el texto constitucional, con la excepción de los territorios de la disposición transitoria segunda, como se estaba entonces. En el discurrir de ese proceso, fue la historia la que se encargó de ir modelando la forma territorial del Estado, y paradójicamente la disfunción del Senado y su absoluta subordinación respecto al Congreso le permitió afrontar los vaivenes de la historia sin que el conjunto del entramado institucional se resintiese: a diferencia de Italia, no hubo en España disconformidad entre Constitución e historia, sino que ésta, a través de los procesos estatuyentes, completó a aquélla en cuanto al diseño territorial, aunque al final lo hiciese en sentido contrario al inicialmente previsto por la Constitución misma. En efecto, con el paso del tiempo, solventadas las dudas sobre la generalización autonómica, la organización territorial propendería claramente hacia la igualación entre los distintos entes autonómicos. Fue a partir de entonces cuando el desencaje del Senado, que había nacido al servicio de unos principios ordenadores de la organización territorial radicalmente distintos, se hizo particularmente evidente. Las reformas llevadas a cabo (como la reforma del Reglamento del Senado de 11 de enero de 1994 por la que se creaba en esta Cámara una Comisión General de las Comunidades Autónomas ${ }^{17}$ ), justamente por circunscribirse a ese modelo de Senado ya superado por la historia, se revelaron limitadas y manifiestamente insuficientes: la reforma constitucional del Senado parecía entonces inevitable. Sin embargo, una circunstancia adicional venía a dificultarla notablemente. En efecto, en los períodos en que se incrementa la competitividad electoral se dificulta considerablemente, por la propia configuración del sistema electoral, la obtención de mayorías holgadas para gobernar; simultáneamente ese mismo sistema electoral disuade a los partidos de ámbito estatal con una débil base electoral de la competición electoral, de manera que, en el peculiar sistema de partidos español, la crucial función de partido bisagra sería asumida por partidos de ámbito no-estatal (nacionalistas o regionalistas), que concentran su electorado en áreas geográficas determinadas obteniendo una representación acorde a su fuerza electoral y que, desde esa posición singularmente estratégica, amparándose en la apertura inicial de la organización territorial y bajo el paraguas del hecho diferencial ${ }^{18}$, aprovechan para

${ }^{17}$ Sobre la Comisión General de las Comunidades Autónomas, véase, por todos, VISIEDO MAZÓN, F. J.: La reforma del Senado: territorialización del Senado. Comisión General de Las Comunidades Autónomas, Madrid, Temas del Senado, Dirección de Estudios y Documentación, Departamento de Publicaciones, Secretaría General del Senado, 1997, pp. 275 y ss. Respecto a las limitaciones de la reforma reglamentaria, SÁNCHEZ AMOR, I.: «El Senado y las Comunidades Autónomas. Crónica de un desencuentro», y AJA, E.: «Perspectivas de la reforma constitucional del Senado», ambos en La reforma del Senado, AA. Vv., Madrid, Senado, Centro de Estudios Constitucionales, 1994, pp. 75 y ss., y 211 y ss. respectivamente.

18

Con relación al «hecho diferencial» constitucionalmente reconocido y amparado, véase LÓPEZ AGUILAR, J. F.: «Constitución, autonomía y hecho diferencial. El Estado autonómico y el "hecho diferencial constitucionalmente relevante" , en Cuadernos de Derecho Público, núm. 2, 1997, pp. 25 y ss. Cfr. también, del mismo autor, Estado autonómico y hechos diferenciales, Madrid, Centro de Estudios Políticos y Constitucionales, 1998. 
reivindicar y obtener para sí nuevas diferencias en una inacabable y perpetua redefinición de la diferencia. Así pues, si no se quiere emprender una inconsistente reforma del Senado, antes será preciso, por así decirlo, acabar la historia (que no ponerle fin, pues siempre cabrá el recurso a la reforma constitucional), esto es, habrá que, resuelta por la historia la duda sobre la generalización-limitación autonómica que el principio dispositivo dejaba abierta, decidirse por uno de los otros dos principios en liza (igualación-diferenciación); y esa decisión -la única que le faltó tomar al constituyente- será indefectiblemente política, pues jurídicamente ambas alternativas son posibles. Por poner sólo un ejemplo, un gran pacto político de estabilización de nuestro mapa competencial, a fin de completarlo y cerrarlo hacia el futuro, sería esencial para complementar y dar sentido práctico a las numerosas propuestas teóricas sobre el modo de configuración del Senado que se han hecho en los últimos años ${ }^{19}$. Así pues, antes de acometer la reforma del Senado, urge tomar esa decisión política fundamental que permita dotar al modelo territorial de unos principios claros e inequívocos (o igualación o diferenciación, una vez disipadas las dudas sobre la generalización) y de ese modo volverlo estable -que no inamovible-, pues sólo entonces y no antes, encaramados en la seguridad jurídica y el pleno valor normativo de la Constitución, podrá saberse con quién y en qué condiciones quiere contarse (aspecto orgánico) y para qué (aspecto funcional) a la hora de configurar el nuevo Senado.

19 Vid., por todos, PORTERo Molina, J. A.: «Contribución al debate sobre la reforma del Senado», en Revista de Estudios Políticos, (Nueva Época), núm. 87, 1995, pp. 81 y ss., y la bibliografía allí citada. 